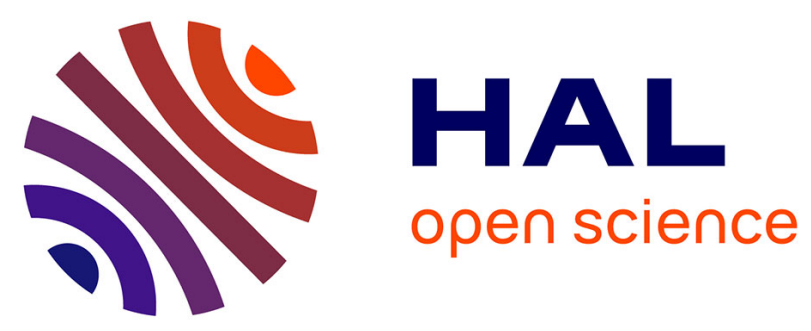

\title{
Electron attachment to uracil: effective destruction at subexcitation energies
}

\author{
G. Hanel, B. Gstir, S. Denifl, P. Scheier, M. Probst, B. Farizon, M. Farizon, E. \\ Illenberger, T.D. Maerk
}

\section{- To cite this version:}

G. Hanel, B. Gstir, S. Denifl, P. Scheier, M. Probst, et al.. Electron attachment to uracil: effective destruction at subexcitation energies. 2003. in2p3-00012726

\section{HAL Id: in2p3-00012726 https://hal.in2p3.fr/in2p3-00012726}

Preprint submitted on 9 Apr 2003

HAL is a multi-disciplinary open access archive for the deposit and dissemination of scientific research documents, whether they are published or not. The documents may come from teaching and research institutions in France or abroad, or from public or private research centers.
L'archive ouverte pluridisciplinaire HAL, est destinée au dépôt et à la diffusion de documents scientifiques de niveau recherche, publiés ou non, émanant des établissements d'enseignement et de recherche français ou étrangers, des laboratoires publics ou privés. 
Electron attachment to uracil: effective destruction at subexcitation energies

G. Hanel ${ }^{\mathrm{a}}$, B. Gstir ${ }^{\mathrm{a}}$, S. Denifl ${ }^{\mathrm{a}}$, P. Scheier ${ }^{\mathrm{a}}$, M. Probst ${ }^{\mathrm{a}}$, B. Farizon ${ }^{\mathrm{b}}$, M. Farizon ${ }^{\mathrm{b}}$, E. Illenberger ${ }^{\mathrm{c}}$ and T. D. Märk ${ }^{\mathrm{a}, \mathrm{d}}$

${ }^{a}$ Institut für Ionenphysik der Universität Innsbruck, Technikerstrasse 25,

A-6020 Innsbruck, Austria

${ }^{\mathrm{b}}$ Institut de Physique Nucléaire de Lyon, IN2P3-CNRS et Université Claude Bernard, F-69622 Villeurbanne

${ }^{c}$ Institut für Chemie - Physikalische und Theoretische Chemie, Freie Universität Berlin, D-14195 Berlin

dalso adjunct Professor at Department of Plasmaphysics, Comenius University, SK-84248 Bratislava, Slovak Republic

\begin{abstract}
We demonstrate that electrons at energies below the threshold for electronic excitation $(<3 \mathrm{eV})$ effectively decompose gas phase uracil generating a mobile hydrogen radical and the corresponding closed shell uracil fragment anion (U-H)'. The reaction is energetically driven by the large electron affinity of the (U-H) radical. This observation has significant consequences for the molecular picture of radiation damage, i. e. genotoxic effects or damage of living cells due to the secondary component of high energy radiation.
\end{abstract}

To be published in Phys.Rev.Letter 
The interaction of high energy radiation ( $\alpha-, \beta-, \gamma$ - rays or heavy ions) with living cells does not in general directly lead to DNA strand breaks. The primary interaction essentially removes electrons from the components of the complex molecular network, i. e., electrons from valence states of the chemical bonds but also electrons from localized inner shells of the individual atoms. As a result of the subsequent charge transfer and energy dissipating processes, chemical bonds can be ruptured generating neutral or ionic radicals as additional secondary species. Electrons as the most abundant secondary species, are created with an estimated quantity of $\approx 4 \times 10^{4}$ electrons per $\mathrm{MeV}$ primary quantum deposited [1]. The larger majority possesses initial kinetic energies up to about $20 \mathrm{eV}$ [2]. In the course of successive inelastic collisions within the medium they are thermalized within $10^{-12} \mathrm{~s}$ before they reach some stage of solvation, then as chemical rather inactive species. Moreover, damage of the genom in a living cell by ionizing radiation is about one third direct and two third indirect [3]. Direct damage concerns reactions directly in the DNA and its closely bound water molecules and indirect damage results from energy deposition in water molecules and other biomolecules in the surrounding of the DNA. It is believed that almost all the indirect damage is due to the attack of the highly reactive hydroxyl radical [4,5].

The importance of reactions of presolvated electrons with amino acids and nucleotides has already been pointed out more than 2 decades ago by time resolved pulse radiolysis experiments [6]. More recently, the ability of free ballistic electrons (3$20 \mathrm{eV}$ ) to efficiently induce single and double strand breaks in supercoiled DNA has clearly been shown by Sanche and co-workers [7]. In these studies it was demonstrated that the DNA strand breaks were initiated by the formation and decay of transient negative ion (TNI) states, localized on the various DNA components (base, phosphate, deoxyribose or hydration water). Resonances in DNA strand break curves were observed in the energy range around $10 \mathrm{eV}$, similar to those TNI states formed by these components in the gas phase or in homogeneous films as exemplified in ref. [7] in the form of measured electron energy-dependent desorption yields of energetic $\mathrm{H}^{-}$from thymine showing a strong peak at around $10 \mathrm{eV}$.

In order to distinguish between intrinsic molecular effects and environmental effects, recently a number of studies about the interaction of primary and secondary radiation (species) with isolated nucleic acid bases has been carried out utilizing recent advances in crossed molecular beam techniques. In addition, several theoretical investigations on the properties of these various DNA components (electron affinities, ionisation energies etc. [8-13]) have been performed. When considering electron attachment studies two series of experiments are noteworthy. Using Rydberg electron attachment Schermann and co-workers [14-16] produced gas phase uracil, thymine and 
adenine molecular anions ascribed to the existence of dipole-bound parent anions. In addition, using as target a mixed uracil-argon cluster beam they were also able to observe weakly bound valence monomer uracil anions $U^{-}$. From calculations and experimental evidence they derived the valence adiabatic electron affinity of uracil to be small but positive $(\approx 70 \mathrm{meV}$ in contrast to an earlier value of $400 \mathrm{meV}$ by Sevilla et al. [10]). This value is close to the calculated value of $86 \mathrm{meV}$ [9] and measured value of $93 \pm 7 \mathrm{meV}$ [17] and 54 $\pm 35 \mathrm{meV}$ [15] of the dipole bound electron affinity. Moreover, minute amounts of uracil anions outside of the peaked Rydberg n-dependencies were interpreted to be due to background anions $(\mathrm{U}-\mathrm{H})^{-}$produced by spurious uncontrolled free electron interactions. In contrast, Illenberger, Sanche and co-workers [18] using a trochoidal electron monochromator in conjunction with a quadrupole mass spectrometer reported recently for thymine and cytosine strong zero energy parent anion signals for free electron attachment to these nucleic bases. Similar results, i.e., the observation of the parent anion, were reported by the same group for various 5-halouracils $(5-\mathrm{X}-\mathrm{U}$; with $\mathrm{X}=\mathrm{Cl}, \mathrm{Br}$ and I) $[19,20]$.

Here we demonstrate that under isolated conditions the RNA base uracil is effectively damaged (dissociated) by very low energy free electrons, i. e., below the threshold for electronic excitation $(<3 \mathrm{eV})$. This is an energy region which was not covered by the previous experiments of Sanche and co-workers where single and double strand breaks in supercoiled DNA induced by free electrons was studied between 3 and $20 \mathrm{eV}$ [7]. Dissociative electron attachment (yielding (U-H) ${ }^{-}$) observed here proceeds via a $\mathrm{C}-\mathrm{H}$ bond rupture generating a mobile and reactive hydrogen radical. Energetically this is accomplished by the surprisingly high electron affinity of the (U-H) radical leading to .

The present experiment is performed in a crossed electron/molecular beam arrangement recently constructed in our laboratory and described in more detail in refs. $[21,22]$. A highly monochromatized electron beam (best values achieved lie at around $30 \mathrm{meV}$; in the present case set to energy resolutions between 80 and $120 \mathrm{meV}$ in order to allow working at low target gas pressures), generated by an electrostatic hemispherical electron monochromator, interacts perpendicularly with an effusive beam of uracil molecules. The uracil beam is generated by heating the uracil powder sample in a Knudsen type oven to $185^{\circ} \mathrm{C}$ and effusing the sublimated molecules through a 1 $\mathrm{mm}$ capillary directly into the collision region. The anions resulting from the electron molecule collisions are extracted from the collision region by a weak extraction potential (at maximum $200 \mathrm{meV} / \mathrm{cm}$ ) and focused to a high resolution quadrupole mass filter (mass range $2000 \mathrm{amu}$ ) where they are mass analyzed and detected by single pulse counting electronics. The electron energy scale and energy resolution has been 
determined by measuring electron attachment to uracil and to $\mathrm{CCl}_{4}$ or $\mathrm{SF}_{6}$ and using the resonant "zero energy peaks " thus obtained for calibration and reference [23,24] (see as an example the curve given in Fig.1).

Figure 2 (top) shows the cross section for the formation of the closed shell anion $(\mathrm{U}-\mathrm{H})^{-}$which is produced mainly at energies below about $5 \mathrm{eV}$. By a comparing anion currents measured under defined pressure conditions in the target region and using the accurately known DEA cross section in $\mathrm{CCl}_{4}$ at $0.8 \mathrm{eV}[25,26]$ we can estimate the DEA cross section in uracil leading to hydrogen radical abstraction to have a value of $\approx 3 \times 10^{-20} \mathrm{~m}^{2}$ at the peak maximum. At higher electron energies, in the range between $\approx 3$ - $12 \mathrm{eV}$ we observe further products $\left(\mathrm{CN}^{-}, \mathrm{OCN}^{-}\right.$and $\left.\mathrm{C}_{3} \mathrm{OH}_{2} \mathrm{~N}^{-}\right)$, however, at significant lower cross sections. These smaller product anions arise from complex decomposition processes involving cleavage of the aromatic ring.

If $U$ assigns the undissociated target molecule uracil, then $(\mathrm{U}-\mathrm{H})^{-}$is the most abundant fragment anion produced via

$$
\mathrm{e}^{-}+\mathrm{U} \rightarrow \mathrm{U}^{\#-} \rightarrow(\mathrm{U}-\mathrm{H})^{-}+\mathrm{H}^{\bullet}
$$

Dissociation of uracil to yield (U-H) ${ }^{-}$at these very low electron energies is a remarkable observation as in Rydberg electron transfer from highly excited atoms only undissociated uracil radical anions were detected [14-16]. Owing to the high dipole moment of uracil $(4.3 \mathrm{D})$ they were ascribed as weakly-bound dipole bound states. It should be noted that in the present experiment we in fact observe a small ion signal at $112 \mathrm{amu}$ (in addition to the signal at 111 which is attributed to the closed shell anion $\left.(\mathrm{U}-\mathrm{H})^{-}\right)$. The signal at $112 \mathrm{amu}$, however, can fully be accounted for by the contribution of the ${ }^{13} \mathrm{C}$ isotope in $(\mathrm{U}-\mathrm{H})^{-}$in its natural abundance. We can hence conclude that the undissociated uracil anion is not formed at any measurable amount in the present crossed beam single collision experiment. Moreover, we also conclude that this behavior is in contrast to recent results obtained for free electron attachment to thymine and cytosine [18], where the major reaction channel was the production of the undissociated nucleic base parent anion, with $\mathrm{CN}^{-}$and $\mathrm{O}^{-}$being the major fragment ions observed though with a factor of 100 lower probability.

The resonances in the shape of the $(\mathrm{U}-\mathrm{H})^{-}$cross section curve indicate that it is formed by resonant dissociative electron attachment (DEA) where $\mathrm{U}^{\#-}$ is the transient negative ion generated by the initial Franck-Condon transition. DEA is in fact the only mechanism to induce a bond cleavage at such low electron energies. The ion yield curve indicates that presumably different negative ion states of the precursor ion $\mathrm{U}^{\#-}$ are involved. It is interesting to note that Burrow and co-workers [11] using electron 
transmission (ET) spectroscopy reported the occurrence of three transient anion states at $0.2 \mathrm{eV}, 1.6 \mathrm{eV}$ and $5.0 \mathrm{eV}$ assigning each of these states to the accommodation of the extra electron into the antibonding $\pi^{*}$ system. Some of the structure presently obeserved may also arise from anion states whose lifetime is sufficiently long to allow nuclear motion [27].

Moreover, reaction (1) can generate 4 different isomeric anions (U-H)'. We have carried out high level ab initio calculations using the G'MP2 [28] method to get information on the energy threshold to generate these different isomeric anions. The computational method is considered to be accurate to better than $\pm 0.1 \mathrm{eV}$, see, for example refs. [28,29]. The calculated energy thresholds are $E(1)=0.8 \mathrm{eV}, E(3)=1.4$ $\mathrm{eV}, E(5)=2.7 \mathrm{eV}$ and $E(6)=2.2 \mathrm{eV}$ where the number in parentheses assigns the $\mathrm{N}$ or $\mathrm{C}$ atom from which $\mathrm{H}$ abstraction takes place (see Fig. 1). These numbers are based on the relation $E(\mathrm{n})=D(\mathrm{n})-E A(\mathrm{n})$ where $D$ assigns the binding energy of the hydrogen atom at the particular site $\mathrm{n}=1,3,5,6$ and $E A$ the electron affinity of the corresponding uracil radical. The explicit numbers are $D(1)=4.4 \mathrm{eV}, E A(1)=3.6 \mathrm{eV}$, $D(3)=5.4 \mathrm{eV}, E A(3)=4.0 \mathrm{eV}, D(5)=5.2 \mathrm{eV}, E A(5)=2.5 \mathrm{eV}$, and $D(6)=5.0 \mathrm{eV}, E A$ $(6)=2.8 \mathrm{eV}$. It is interesting to note that a very narrow peak is observed close to zero $\mathrm{eV}$ which is below the threshold for the energetically lowest channel. The origin of this peak is not completely clear as its intensity also depends on the presence of the calibration gas $\left(\mathrm{CCl}_{4}\right)$. There is, however some $(\mathrm{U}-\mathrm{H})^{-}$signal present close to zero eV also in the case when the calibration gas $\mathrm{CCl}_{4}$ is completely absent in the target region.

It is well known that endothermic DEA reactions can exhibit distinct zero energy peaks due to transitions from vibrationally excited states of the neutral molecule (hot band transitions). Due to the particular conditions in DEA (reciprocal energy dependence of the cross section, etc.) these threshold peaks can appreciably contribute to the process even at very moderate population of vibrationally excited levels [30]. It is important to note that if the zero eV contribution is due to a hot band, it would probably not have any significance in a real biological environment due to the much lower temperature.

We note that in DEA experiments to 5-bromouracil [19] and further 5-halouracils $[19,20]$ in fact very effective pathways of dissociative attachment at virtually $0 \mathrm{eV}$ were identified. In the case of bromouracil $\left(\mathrm{U}_{\mathrm{Br}}\right)$ the following complementary reactions:

$$
\begin{aligned}
\mathrm{e}^{-}(0 \mathrm{eV})+\mathrm{U}_{\mathrm{Br}} \rightarrow \mathrm{U}_{\mathrm{Br}}^{\#-} & \rightarrow\left(\mathrm{U}_{\mathrm{Br}}-\mathrm{Br}\right)^{\bullet}+\mathrm{Br}^{-} \\
& \rightarrow\left(\mathrm{U}_{\mathrm{Br}}-\mathrm{Br}\right)^{-}+\mathrm{Br}^{\bullet}
\end{aligned}
$$


with (2a) the most abundant channel at an estimated cross section of $6 \times 10^{-18} \mathrm{~m}^{2}$. Note that in our assignment the radical $\left(\mathrm{U}_{\mathrm{Br}}-\mathrm{Br}\right)^{\bullet}$ corresponds to $(\mathrm{U}-\mathrm{H})^{\bullet}$, accordingly for the closed shell anions $\left(\mathrm{U}_{\mathrm{Br}}-\mathrm{Br}\right)^{-} \equiv(\mathrm{U}-\mathrm{H})^{-}$. Since Br possesses a high electron affinity (3.06 $\mathrm{eV}$ ) reaction (2a) was expected to operate with high efficiency at low electron energies. Reaction (2b) is also operative at zero eV (though at only $6 \%$ of the effectivity of (2a)) and from that it was already concluded (energy balance of DEA to the different halouracils) that the electron affinity of the (U-H) radical must be at least in the range of about $3.0 \mathrm{eV}$ [19]. This value is in accordance with values obtained in the above mentioned ab initio calculations.

It has been known for many years that substitution of thymine by bromouracil in the genetic sequence of cellular DNA leads to a greater sensitivity to ionizing radiation $[31,32]$ without changing the gen expression in unradiated cells. Bromouracil hence possesses potential application as a tumor sensitizer in cancer therapy. It is interesting to note that uracil is damaged at electron energies below $3 \mathrm{eV}$ with a cross section of $3 \times 10^{-}$ ${ }^{20} \mathrm{~m}^{2}$. While this cross section is about $25 \%$ of the geometrical cross section of the molecule and in the range of typical electron impact (dissociative) ionisation cross sections at higher electron energies [33] it is by more than two orders of magnitude below that for the break up in chlorouracil (as determined also in the present study to be about $5 \times 10^{-18} \mathrm{~m}^{2}$ ) and the other halouracils (see $\left.[19,20]\right)$. One may then conclude that the initial mechanism for direct DNA or RNA damage is bond cleavage by low energy secondary electrons. It should be mentioned, however, that coupling of the molecule to an environment can considerably change the cross section, i.e., leading to smaller or larger cross sections $[34,35]$. In the case of DEA, This reaction is much more effective in the radiosensitizers as obvious from the above cross section values. One point remains noteworthy: while the closed shell anion $\left(\mathrm{U}_{\mathrm{Br}}-\mathrm{Br}\right)^{-} \equiv(\mathrm{U}-\mathrm{H})^{-}$formed via reaction (2b) is defined by the position of the $\mathrm{Br}$ atom in 5-bromouracil, reaction (1) can as mentioned above generate 4 different isomeric anions $(\mathrm{U}-\mathrm{H})^{-}$and be responsible for the structures in the $(\mathrm{U}-\mathrm{H})^{-}$ion yield. For the problem of RNA damage the essential question is to which degree the different isomers and hence the different $\mathrm{C}-\mathrm{H}$ and N-H bonds are involved. Such problems can be tracked by isotope experiments in combination with ab initio calculations and are underway in our laboratories.

In summary we have demonstrated that ultralow energy electrons induce hydrogen radical abstraction via DEA in uracil. Due to its low mass the hydrogen radical can be considered as being very mobile. Moreover, in the dissociating transient negative ion any translational excess energy will nearly exclusively be transferred to the light hydrogen atom (via the principle of linear momentum conservation more than $99 \%$ ) thus facilitating the removal of the hydrogen radical in this DEA reaction. One can 
therefore predict that also within a dissipative environment like in a living cell reaction (1) will remain to a large degree dissociative.

\section{Acknowledgments}

This work is supported by the Austrian FWF and ÖNB, Wien, the Deutsche Forschungsgemeinschaft, Bonn, the Austrian-French Amadee Programme, Wien and Paris, and the European Commission, Brussels.

\section{References}

1. 1. International Commission on Radiation Units and Measurements, ICRU Report 31 (ICRU, Washington, DC, 1979).

2. V. Cobut, Y. Fongillo, J. P. Patau, T. Goulet, M.-J. Fraser, and J.-P. Jay-Gerin, Radiat. Phys. Chem. 51, 229 (1998), and references cited therein.

3. B. D. Michael and P. A. O’Neill. Science 287, 1603 (2000).

4. C. M. DeLara, T. J. Jenner, K. M. S. Townsend, S.J. Marsden, and P. O'Neill, Radiat. Res. 144, 43-49 (1995).

5. J.K.Wolken, E.A.Syrstad, S.Vivekananda and F.Turicek, J.Am.Chem.Soc., 123 (2001) 5804

6. J. E. Aldrich, K. Y. Lam, P. C. Shragge, and J. W. Hunt, Radiat. Res. 63, 42 (1975).

7. B. Boudaïffa, P. Cloutier, D. Hunting, M. A. Huels and L. Sanche, Science 287, 1658 (2000).

8. J.M.Younkin, L.J.Smith and R.N.Compton, Theor.Chim.Acta, 41, 157 (1976)

9. .N.A.Oyler and L.Adamowicz, J.Phys.Chem., 97, 11123 (1993)

10. M.D.Sevilla, B.Besler and A.O.Colson, J.Phys.Chem., 99, 1060 (1996)

11. K. Aflatooni, G. A. Gallup and P. D. Burrow, J. Phys. Chem. 102, 6205 (1998)

12. O.Dolgounitcheva, V.G.Zakrzewski and J.V.Ortiz, Chem.Phys.Lett., 307, 220 (1999)

13. S.D.Wetmore, R.J.Boyd and L.E.Eriksson, Chem.Phys.Lett., 343, 151 (2001)

14. C.Desfrancois, H.Abdoul-Carime, N.Khelifa and J.P.Schermann, Phys.Rev.Letters, 73, 2436 (1994)

15. C.Desfrancois, H.Abdoul-Carime and J.P.Schermann, J.Chem.Phys., 104, 7792 (1996)

16. C. Desfrancois, V. Periquet, Y. Bouteiller, and J. P. Schermann, J. Phys. Chem. 102, 1274 (1998).

17. J.H.Hendicks, S.A.Lyapustina, H.L.de Clerq, J.T.Snodgrass and K.H.Bowen, J.Chem.Phys., 104, 7788 (1996) 
18. M. A. Huels, I. Hahndorf, E. Illenberger, and L. Sanche J. Chem. Phys. 108, 1309 (1998).

19. H. Abdoul-Carime,M.A., Huels,F., Brüning,E. Illenberger\& ,L. Sanche . J. Chem. Phys. 113, 2517 (2000).

20. H. Abdoul-Carime, M. A. Huels, L. Sanche and E. Illenberger, J. Am. Chem. Soc. 123, 5354 (2001).

21. G. Denifl, D. Muigg, A. Stamatovic, T.D. Märk, Chem. Phys. Lett., 288, 105 (1998)

22. G. Hanel, B. Gstir, T. Fiegele, F. Hagelberg, K. Becker, P. Scheier, A. Snegursky, and T. D. Märk, J. Chem. Phys. 116, 2456 (2002).

23. S. Matejcik, G. Senn, P. Scheier, A. Kiendler, A. Stamatovic and T.D. Märk, J. Chem. Phys., 107, 8955 (1997)

24. G. Senn, J.D. Skalny, A. Stamatovic, N.J. Mason, P. Scheier, T.D. Märk, Phys. Rev. Lett., 85, 5028 (1999)

25. S.C.Chu, P.D.Burrow, Chem.Phys.Lett., 172, 17 (1990)

26. K.Aflatooni, P.D.Burrow, J.Chem.Phys., 113, 1455 (2002)

27. K.D.Jordan and P.D.Burrow, Acc.Chem.Res., 11, 341 (1978)

28. L.A.Curtiss, K.Raghavachari and J.A.Pople, J.Chem.Phys, 98, 1293 (1993)

29. R.D.Bach, P.Y.Ayala and H.B.Schlegel, J.Am.Chem.Soc., 118, 12758 (1996)

30. I.Hahndorf and E.Illenberger, Int.J:Mass Spectr.Ion Proc., 167/168 (1997) 87

31. S. Zamenhof, R. DeGiovanni and S. Greer, Nature 181, 827 (1958).

32. T. S. Lawrence, M. A. Davis, J. Maybaum, P. L. Stetson, and W. D. Ensminger, Radiat. Res. 123, 192 (1990).

33. T.D.Märk and G.H.Dunn, Electron impact ionization, Springer, Wien, (1985).

34. D.V.Klychachko, M.A.Huels and L.Sanche, Radiation Research 151 (1999) 177

35. E. Illenberger, Electron Attachment Processes in Free and Bound Molecules

in Photoionization and Photodetachment, Part II, pp 1063 - 1160. Advanced Series in Physical. Chemistry - Vol. 10B., C. - Y. Ng, ed., World Scientific, Singapore (2000).

Figure captions:

Fig.1

Product ion yield for (U-H) ${ }^{-}$for electron attachment to gas-phase uracil (full line) as a function of incident energy measured with an energy resolution of about $80 \mathrm{meV}$. Also shown for comparison (and as a calibration gas) the $\mathrm{SF}_{6}{ }^{-}$anion yield (point-dashed line) obtained by electron attachment to the simultaneously present $\mathrm{SF}_{6}$ gas.

Fig.2 
Absolute partial cross sections for electron attachment to gas-phase uracil as a function of incident energy. The curves shown here constitute an average of several experimental runs (such as the one shown in Fig.1) taken at energy resolutions between 100 and 120 meV. 


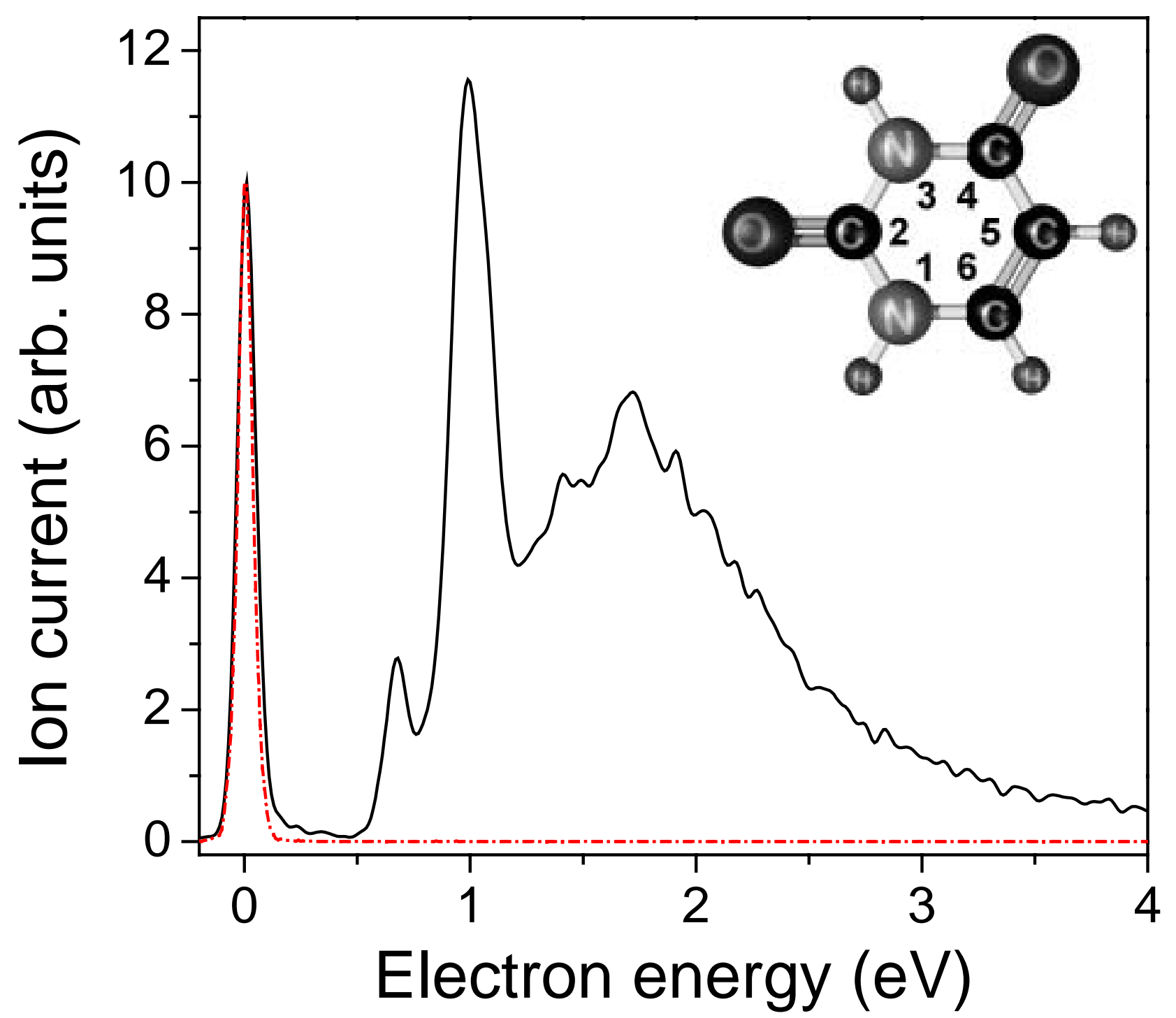




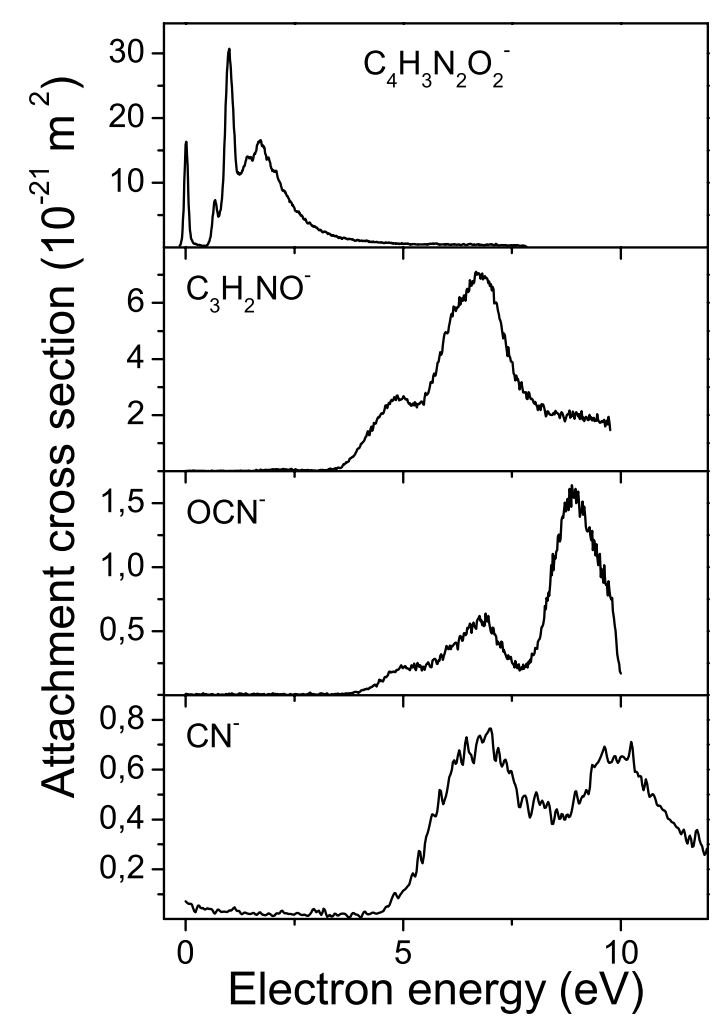

